\title{
Long-Term Temporal Variability of the Freshwater Discharge and Water Levels at Patos Lagoon, Rio Grande do Sul, Brazil
}

\author{
G. P. Barros ${ }^{1}$ and W. C. Marques ${ }^{2}$ \\ ${ }^{1}$ Laboratory of Physical, Coastal and Estuarine Oceanography, Institute of Oceanography, Federal University of Rio Grande, \\ P.O. Box 474, 96200-900 Rio Grande, RS, Brazil \\ ${ }^{2}$ Institute of Mathematics, Statistics and Physics, Federal University of Rio Grande, P.O. Box 474, 96200-900 Rio Grande, RS, Brazil
}

Correspondence should be addressed to G. P. Barros, gustavobarros@furg.br

Received 5 January 2012; Revised 4 April 2012; Accepted 22 April 2012

Academic Editor: Zdenek Martinec

Copyright ( 2012 G. P. Barros and W. C. Marques. This is an open access article distributed under the Creative Commons Attribution License, which permits unrestricted use, distribution, and reproduction in any medium, provided the original work is properly cited.

\begin{abstract}
The aim of this study is to investigate the importance of freshwater discharge as a physical forcing in Patos Lagoon at timescales longer than one year, as well as identify the temporal variability of the dominant processes in freshwater discharge and water levels along the Patos Lagoon. Due to its proximity to the mouth, the water level at the estuary is influenced by the remote effects associated with the adjacent ocean circulation and wave climatology, reducing the observed correlation. At the lagoonar region a high correlation is expected because interannual data is being used, reducing the influence of the wind. Cross wavelet technique is applied to examine the coherence and phase between interannual time-series (South Oscillation Index, freshwater discharge and water levels). The freshwater discharge of the main tributaries and water levels in Patos Lagoon are influenced by ENSO on interannual scales (cycles between 3.8 and 6 years). Therefore, El Niño events are associated with high mean values of freshwater discharge and water levels above the mean. On the other hand, La Niña events are associated with low mean values of freshwater discharge and water levels below the mean.
\end{abstract}

\section{Introduction}

The influence of freshwater discharge in coastal areas is manifested in different timescales and in many physical, chemical, or geological processes [1-5], affecting primary production, stimulating benthonic remineralization, and creating spatial patterns of production due to the high availability of suspended sediment and the increase of water turbidity of continental origin.

Freshwater discharge is also responsible for controlling water quality by changing the quantities and compositions of organic and inorganic compounds, affecting the time it takes to transport materials and the water residence time [6-8]. Their influences can be observed in the control of residual circulation, inducing spatial and temporal circulation patterns that may also be reflected in the processes of transport, stratification, and shear in the water column $[9,10]$. Low precipitation and freshwater outflow, associated with La Niña years, are responsible for increasing the abundance of species in the Patos Lagoon estuary. On the other hand, during El Niño years, the high precipitation and freshwater discharge are associated with a reduction in the abundance of marine species in the estuary [11].

The study of the influence of freshwater discharge in the dynamics of coastal regions at long period timescales is not easily accomplished, as long data series are necessary that are often not available. However, knowledge of the importance of this forcing is essential for proper management of coastal environments.

Most studies on the dynamics of the Patos Lagoon, situated in the southernmost part of Brazil, are limited to studies that consider the effect of wind and fluvial discharge at synoptic timescales [12-17]. Long-term dynamics studies are hampered by the absence of simultaneous data, especially water levels data along the lagoon.

Therefore, the aim of this study is to investigate the importance of freshwater discharge as a physical forcing in Patos Lagoon at timescales longer than one year, as well as 


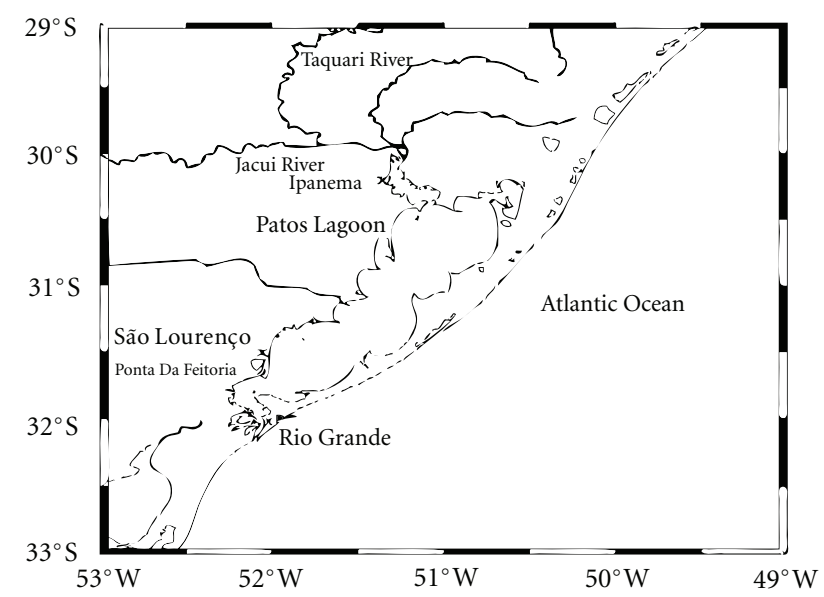

Figure 1: Patos Lagoon, main contributing rivers and water levels stations.

identify the temporal variability of the dominant processes in freshwater discharge and water levels along the Patos Lagoon.

1.1. Study Area Description. Patos Lagoon is a choked coastal lagoon located in the southernmost part of Brazil, between $30^{\circ}-32^{\circ} \mathrm{S}$ latitude and $50^{\circ}-52^{\circ} \mathrm{W}$ longitude (Figure 1) [18]. The lagoon has a surface area of $10,360 \mathrm{~km}^{2}$ and drains a watershed of approximately $201,626 \mathrm{~km}^{2}$. The lagoon region covers about $90 \%$ of the total area and the estuarine region covers the other $10 \%$. Both regions are separated by the sand banks of Ponta da Feitoria [18].

The main contributing rivers are Taquari and Jacuí which flows through the Guaíba River and Camaquã River, which flows into the central region of the lagoon. The mean annual discharge of those rivers is $2400 \mathrm{~m}^{3} \mathrm{~s}^{-1}$ [19].

The freshwater discharge of the Patos Lagoon shows a typical pattern of temperate regions, also presenting temporal variations on interannual scales [19]. Extreme discharge events of $16,000 \mathrm{~m}^{3} \mathrm{~s}^{-1}$ have been observed by Marques et al. [19] on the year of 1940 during the winter.

Over synoptic timescales, wind action is the most effective forcing in Patos Lagoon's circulation [14]. However, studies that show the importance of freshwater discharge in the dynamics of the Patos Lagoon, especially in long period timescales, still must be further explored.

\section{Methodology}

For this study it was used freshwater discharge, water levels, and South Oscillation Index (SOI) data sets. The SOI was used for the purpose of investigating the relation between the occurrence of the natural phenomenon El Niño Southern Oscillation (ENSO) and the anomalies observed in freshwater discharge and water levels data.

The ENSO phenomenon is the natural climate fluctuation with the most intense interannual scale [20]. The Southern Oscillation Index, or SOI, gives an indication of the development and intensity of El Niño or La Niña events in the Pacific Ocean. Sustained negative values of the SOI greater than -8 often indicate El Niño episodes. Sustained positive values of the SOI greater than +8 are typical of a $\mathrm{La}$ Niña episode.

The method used in this study is the same used by the Australian Bureau of Meteorology, which is the Troup SOI that is the standardised anomaly of the Mean Sea Level Pressure (MSLP) difference between Tahiti and Darwin. It is calculated as follows:

$$
\mathrm{SOI}=10\left[\frac{\left(P_{\text {diff }}-P_{\text {diffav }}\right)}{\operatorname{SD}\left(P_{\text {diff }}\right)}\right]
$$

where $P_{\text {diff }}$ is the average Tahiti MSLP for the month minus the average Darwin MSLP for the month, $P_{\text {diffav }}$ is the longterm average of $P_{\text {diff }}$ for the month in question, and $\mathrm{SD}\left(P_{\text {diff }}\right)$ is the long-term standard deviation of $P_{\text {diff }}$ for the month in question.

Historical data of freshwater discharge and SOI covers the period between 1940 and 2010, and historical data of water levels covers the period between 1985 and 2010 .

The freshwater discharge of the rivers Jacuí and Taquari, as well as water levels for the Ipanema, São Lourenço, and Rio Grande stations was obtained on the Brazilian National Water Agency website (ANA-http://www.ana.gov.br/). Figure 1 shows the location of these measuring stations. The total freshwater discharge was represented by the sum of the contributing river flows mentioned above. The SOI monthly means were obtained on the Australian Bureau of Meteorology website (http://www.bom.gov.au/).

The monthly means of the data used in this work were transformed into annual means and later arranged in time series. The most important variability cycles of the time series were investigated using the wavelet analysis, and the possible linear relation between variables was investigated using the cross-wavelet analysis according to Torrence and Compo [21]. Wavelet analysis is a useful tool for analyzing time series with many different timescales or changes in variance. The wavelet transform can be used to analyze time series that contain nonstationary power at many different frequencies [22].

The steps used in the paper for the wavelet analysis are the same listed by Torrence and Compo [21]. First, all the time series were padded with zeros at the end. This has to be done because we are using finite-length time series; errors will occur at the beginning and end of the wavelet power spectrum, as the Fourier transform assumes the data is cyclic [21]. After that the scale (interannual with a length of 70 years) and function were chosen, in this case the Morlet which is a complex wavelet. The wavelet function at each scale was normalized to have unit energy to ensure that each scale is directly comparable to each other and to the transforms of other time series. The cone of influence and the Fourier wavelength at that scale were determined. The cone of influence is the region of the wavelet spectrum in which edge effects become important, so that everything below the cone of influence (located on the edges) is considered an error. The steps between normalization and determining the cone of influence and Fourier wavelength are repeated, and afterwards the padding is removed. The 95\% confidence level was derived using the chi-squared distribution assuming 


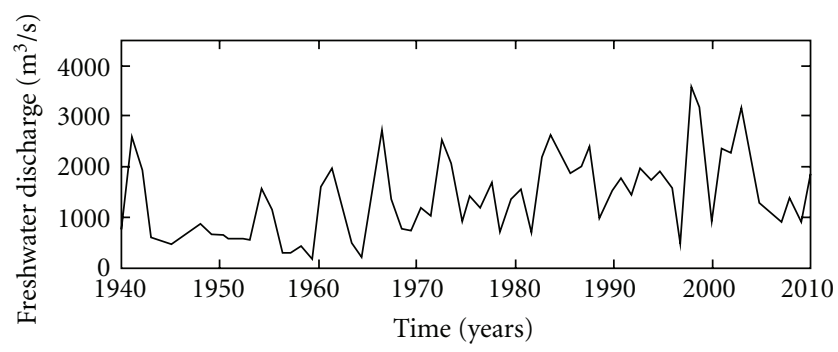

(a) Jacuí and Taquari rivers

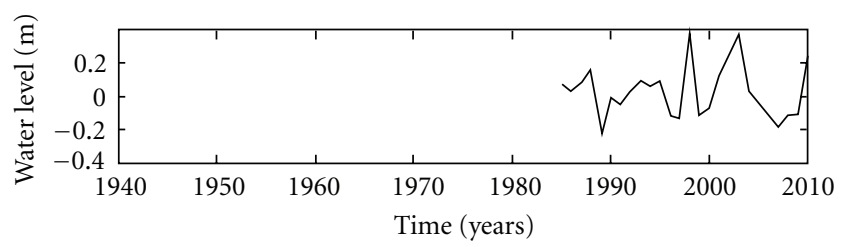

(c) Ipanema

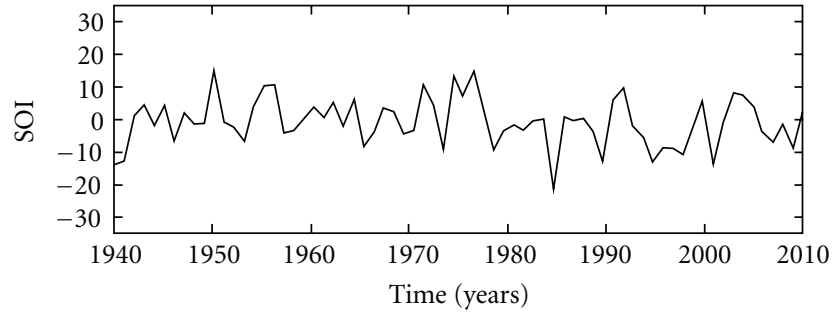

(b) SOI

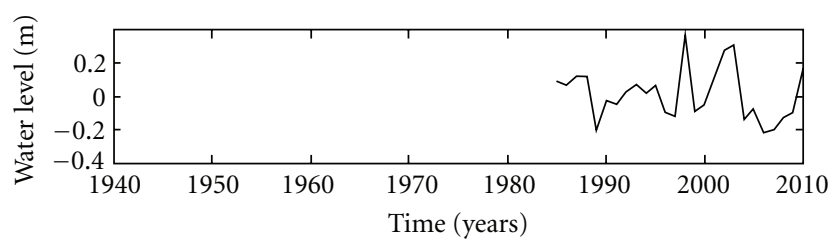

(d) São Lourenço

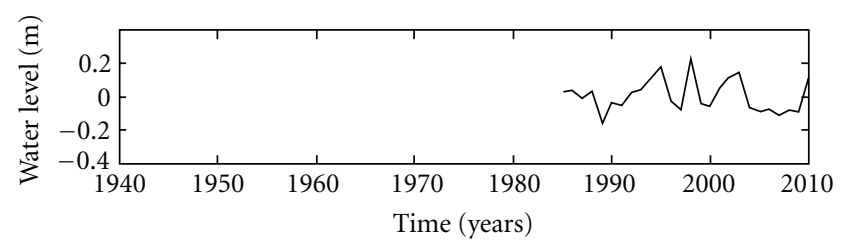

(e) Rio Grande

Figure 2: Temporal series of freshwater discharge (a) and SOI (b) for the period between 1940 and 2010. Temporal series of water levels at Ipanema (c), São Lourenço (d), and Rio Grande (e) between 1985 and 2010.

a red noise spectrum with $\alpha=0.75$. All the equations, steps, and other theoretical material on wavelets can be found on Torrence and Compo [21].

The methods used in the statistical analysis are described in Emery and Thompson [23] and the filling of the gaps in water level time series, between 1940 and 1985, was conducted by creating a polynomial model to describe the water level as a function of freshwater discharge using the least squares method. This method can be applied because any function can be written as a complete set of orthogonal functions that are independent in this function space.

The regression method has been applied successfully by other authors. Kendall and Blanton [24] used it to calculate the salinity as a function of sea surface temperature along the coast of Georgia. Pilson [25] used it to obtain an average residence time for Narragansett Bay, USA. Simpson et al. [26] used the regression method to estimate currents as a function of the wind along the shore of the North Sea. Bourgault and Koutitonsky [27] applied it to calculate freshwater discharge as a function of water levels in St. Lawrence's estuary, USA.

The function base of the water levels $\eta(x)$ can be written with a finite number $(m)$ of convergent series of orthogonal functions $F_{n}(x)$ :

$$
\eta(x)=\sum c_{n} F_{n}(x), \quad n=0,1, \ldots, m,
$$

where $c_{n}$ are the coefficients. Any data set can be divided into a deterministic part $E(x)$ and a random part $\epsilon$ :

$$
\eta(x)=E(x)+\epsilon .
$$

According to Emery and Thompson [23], the ordinary least squares method can be used to find a polynomial relation of a random variable $\eta$ (variable dependent) with a function of nonrandom variables $x^{N}$ (independent variables) as

$$
\eta(x)=b_{0}+b_{1} x+\cdots+b_{N} x^{N}+\epsilon,
$$

where $N$ is the order of the polynomial adjustment and $b_{0}, b_{1}, \ldots, b_{N}$ are adjustment coefficients. Under these conditions, a third order polynomial model $(m=4)$ of water levels $\eta_{D}(D(t))$ can be written as a function of the freshwater discharge $D(t)$ as

$$
\begin{aligned}
\eta_{D}(D(t))= & b_{m} D(t)^{m-1}+b_{m-1} D(t)^{m-2}+b_{m-2} D(t)^{m-3} \\
& +b_{m-3} D(t)^{m-4} .
\end{aligned}
$$

The polynomial model described above was used to calculate the deterministic part of the water levels as a function of the freshwater discharge. And the third order adjustment was chosen through the stability tests performed on the polynomial model.

\section{Results}

3.1. Time Series and Regression Analysis. The annual mean time series of total freshwater discharge, SOI, and water levels for the different points along the Patos Lagoon are represented in Figure 2. Comparing the series of total freshwater discharge (Figure 2(a)) with the SOI series (Figure 2(b)) 


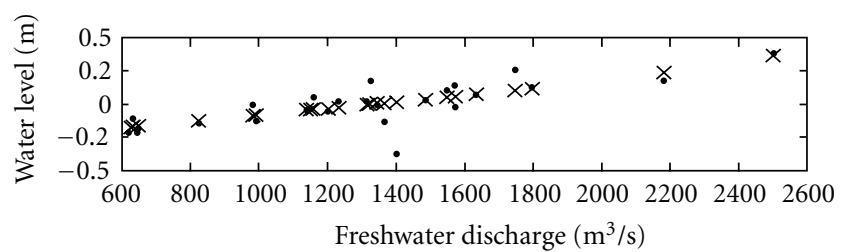

Observed $\times$ Adjusted

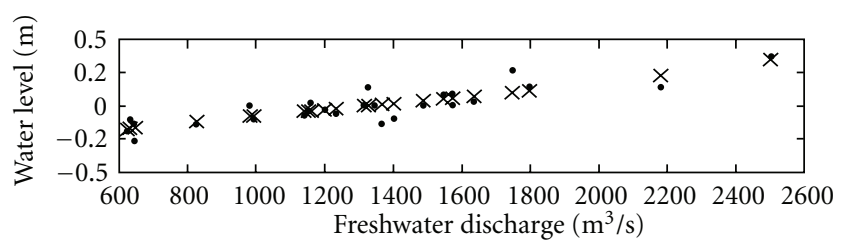

Observed $\times$ Adjusted

(a) Ipanema

(b) São Lourenço

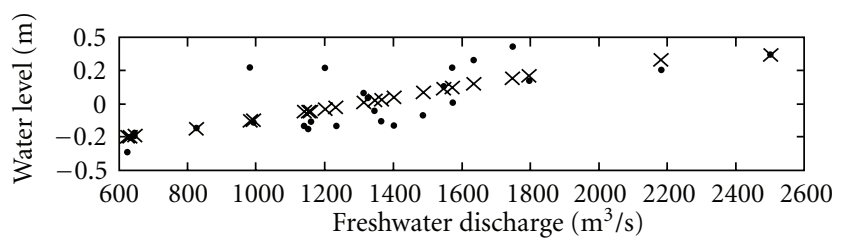

- Observed

$\times$ Adjusted

(c) Rio Grande

FIGURE 3: Dispersion diagram between freshwater discharge and water levels at Ipanema (a), São Lourenço (b), and Rio Grande (c) between 1985 and 2010. The best third order adjustment is represented by the crosses in the figures.

it can be observed that negative values of SOI (El Niño years) are associated, with some time delay, to higher mean values of freshwater discharge (e.g., 1940-41, 1966-67, 1986-87, and 1998-99). Likewise, positive values of SOI (La Niña years) are related to lower mean values of freshwater discharge in Patos Lagoon (e.g., 1958-59, 1977-78, and 1985-86), indicating an inverse relationship between SOI and freshwater discharge intensity in the region, also presenting time delay.

The delay between ENSO events and precipitation anomalies varies from year to year and presents different patterns between El Niño and La Niña events. The delay is usually lower than a year so it is not possible to observe it on interannual time series. Further studies are required to better investigate the delay between ENSO events, precipitation and freshwater discharge anomalies in Patos Lagoon. Other authors have investigated this delay on the south region of Brazil, giving us important regional information that will be discussed later.

In Figure 2(a) it can be observed that there are peaks of freshwater discharge (e.g., 1962 and 1984) that are not associated with El Niño events. These peaks may be explained by the seasonal pattern in the region, associated with a large number of front cold passages in the years of 1962 and 1984 that resulted in high precipitation and consequently an increase in the freshwater discharge, without the influence of El Niño events.

Regarding the water levels (Figures 2(c), 2(d), and 2(e)) it can be observed a direct relationship with the freshwater discharge, where high (low) intensity means are associated with levels above (below) the mean. Two peaks can be observed in Figures 2(c), 2(d), and 2(e), on 1998-99 and 2002-2003, which where years that presented really strong El Niño events. The same pattern is observed in all stations,
Table 1: Polynomial coefficients (coef) of the measurement stations.

\begin{tabular}{lccc}
\hline Coef & Ipanema & São Lourenço & Rio Grande \\
\hline$b_{4}$ & $4.1181 * 10^{-11}$ & $4.6837 * 10^{-11}$ & $-4.2680 * 10^{-11}$ \\
$b_{3}$ & $-1.4166 * 10^{-7}$ & $-1.8447 * 10^{-7}$ & $1.7411 * 10^{-7}$ \\
$b_{2}$ & $3.9458 * 10^{-4}$ & $4.6982 * 10^{-4}$ & $-6.2080 * 10^{-4}$ \\
$b_{1}$ & $-3.7211 * 10^{-2}$ & $-4.0599 * 10^{-2}$ & $-1.2057 * 10^{-1}$ \\
\hline
\end{tabular}

with the Rio Grande station showing lower water level values, due to the influence of the ocean on the estuarine region. The regression analysis between freshwater discharge and water level data between the years of 1985 and 2010 shows well this relationship.

The dispersion analysis (Figure 3) confirms a direct relationship between the variables, on analyzed timescales, where levels below (above) the mean are associated with freshwater discharge lower (higher) than $2000 \mathrm{~m}^{3} \mathrm{~s}^{-1}$. The Rio Grande region presents the lowest correlation with the freshwater discharge, and some points do not follow this pattern. This difference is expected due to the influence of the remote effects associated with the adjacent ocean circulation and wave interaction, reducing the freshwater discharge dominance over the water level in the estuary.

The polynomial adjustment obtained (Figure 3 ) follows a similar pattern of a cubic parabola, but there is a difference in the concavity orientation between the estuary region and the lagoon. This pattern is evident in the polynomial coefficients signs that are presented in Table 1. It can be seen that São Lourenço and Ipanema have positive values for $b_{2}$ and $b_{4}$ and negative values for $b_{1}$ and $b_{3}$, while Rio Grande shows opposite signals (except for $b_{1}$ ). The stability of the polynomial 


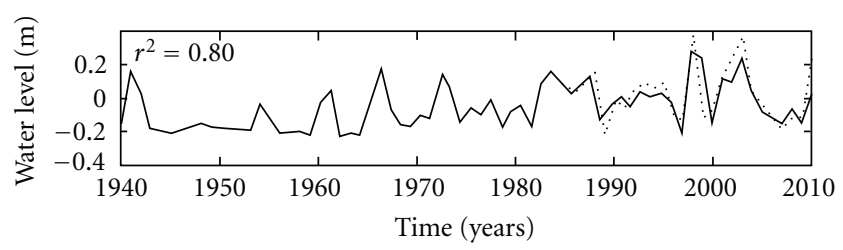

(a) Ipanema

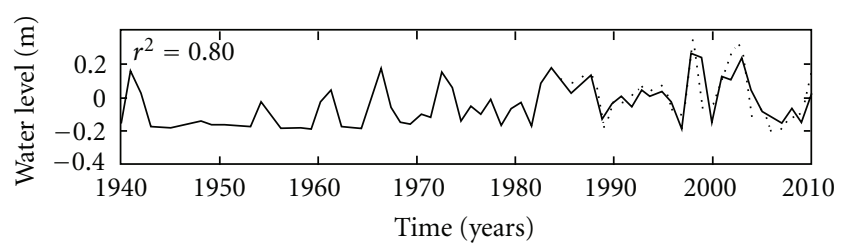

(b) São Lourenço

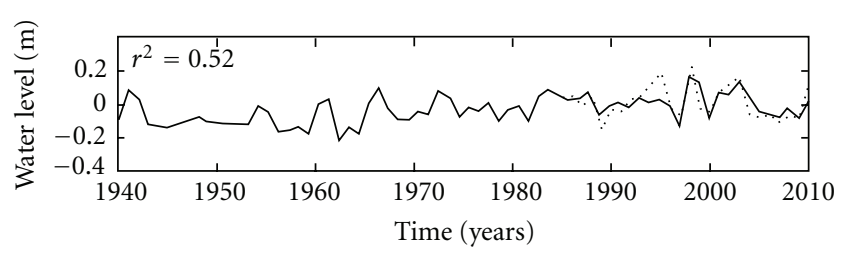

(c) Rio Grande

FiguRE 4: Water levels series calculated between 1940 and 2010 (solid line) and observed water levels series between 1985 and 2010 (dotted line) in Ipanema (a), São Lourenço (b), and Rio Grande (c). Coefficients of determination $\left(r^{2}\right)$ are presented in the figures.

model was tested by applying it to fill the gaps (45 years) found in water level time series between the 1940 and 1985 years (Figure 4).

Analysis of the results showed that freshwater discharge of the main contributing rivers in the Patos Lagoon explains, on interannual scales, more than $80 \%\left(r^{2}=0.80\right)$ of the water levels variability observed in the lagoon region, which is expected because interannual data is being used. At the estuary, freshwater discharge explains around 50\% $\left(r^{2}=\right.$ 0.52) of the water levels variability, which is also expected due to its proximity to the mouth and consequent effects associated with the adjacent ocean circulation and wave climatology.

On Figure 4 it is possible to observe that the calculated water level follows a pattern very similar to the observed. All the stations present high and low values of water level on the same years, showing that the freshwater discharge is controlling the water levels on the three stations. A period of low fluctuation is observed between 1943 and 1960, and a high-oscillations period is present between the years of 1983 and 2003. Ipanema (Figure 4(a)) and São Lourenço (Figure 4(b)) show almost an identical fluctuation of the water levels due to its similar correlation coefficients $(r)$ with the freshwater discharge: 0.89225 and 0.89657 , respectively. Consequently, the coefficient of determination $\left(r^{2}\right)$ is the same: 0.80 .

Table 2 indicates that Rio Grande station demonstrates a lower correlation coefficient (0.72136), which is reflected on Figure 4(c), where the water levels show lower amplitude compared with the other stations, indicating that other forcing is acting in the region. The inverse relationship between ENSO and the freshwater discharge can be observed in the negative signal of the correlation coefficient between both parameters. The correlation coefficient between ENSO and the freshwater discharge is the lowest $(r=-0.66591)$, indicating that the freshwater discharge is influenced by other forcing, such as the passage of cold fronts in the region.

On Figure 5 it can be observed the difference between the observed and calculated water levels in all stations.
TABLE 2: Correlation coefficients between ENSO and freshwater discharge and between discharge and water levels.

\begin{tabular}{lcccc}
\hline Cor. Coef. & ENSO & Ipanema & S. Lourenço & R. Grande \\
\hline Discharge & -0.66591 & 0.89225 & 0.89657 & 0.72136 \\
\hline
\end{tabular}

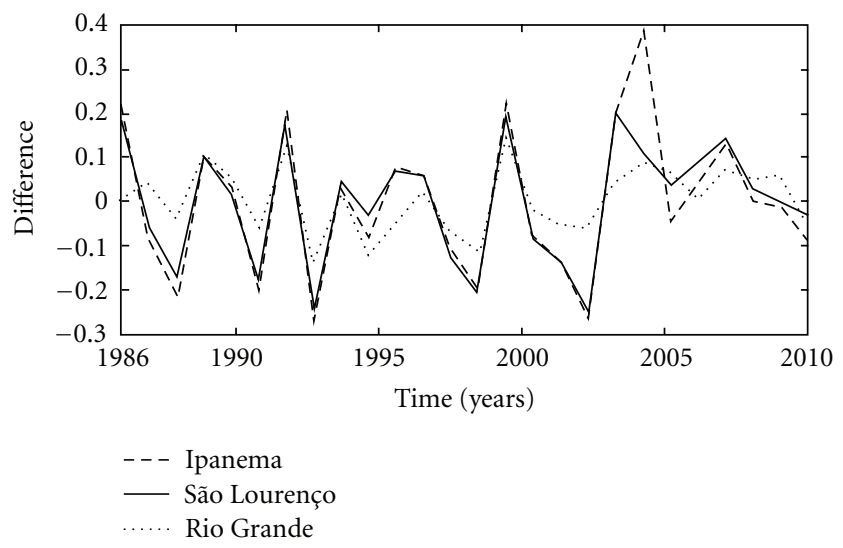

Figure 5: Difference between the observed and calculated water levels between 1986 and 2010 for the stations Ipanema, São Lourenço, and Rio Grande.

The lowest variation is presented by the Rio Grande station, probably because the water level fluctuation in the region is influenced by other forcing. The Ipanema and São Lourenço stations have a similar pattern, but the first demonstrated a peak of difference between 2003 and 2005, caused most likely by an error in the data collected.

3.2. Statistical Analysis. Figure 6(a) presents the inverse relationship between SOI and freshwater discharge intensity. Negative index values (El Niño years) are associated with high discharges, while positive index values are related to low discharges (La Niña years). The strong inverse relationship 


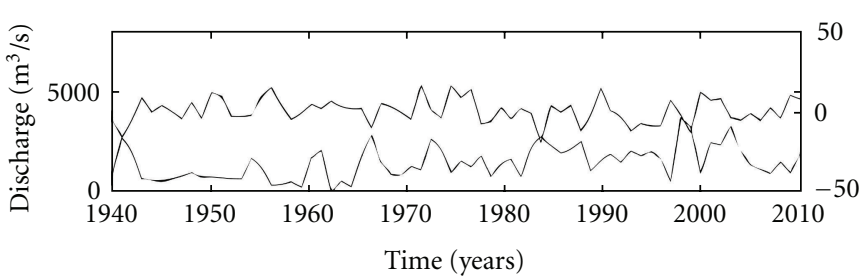

(a)

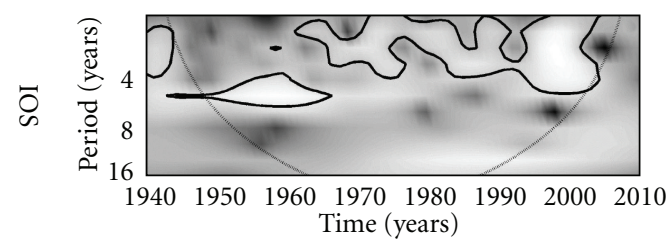

(b)

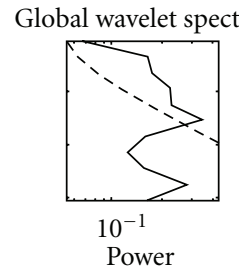

(c)

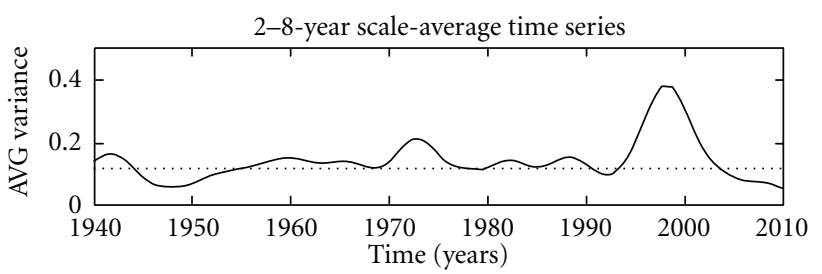

(d)

FIGURE 6: Freshwater discharge and SOI series (a). Cross-wavelet power between freshwater discharge and SOI; the dotted line indicates the cone of influence (b). Global wavelet spectrum between freshwater and SOI (c) and the average variance on scales between 2 and 8 years (d).

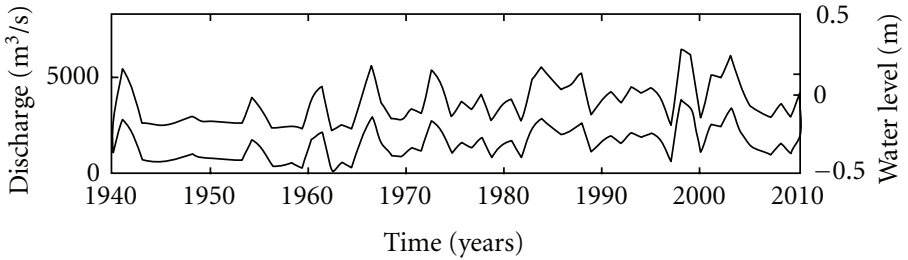

(a)

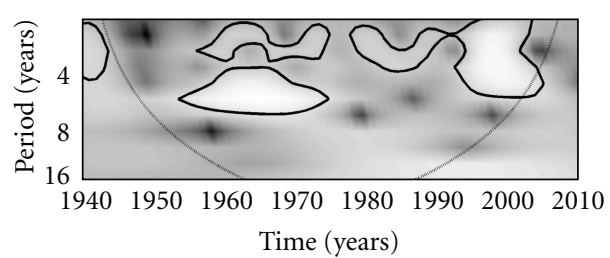

(b)

Global wavelet spectrum

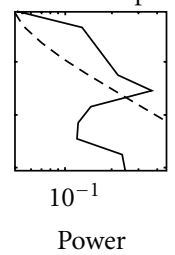

(c)

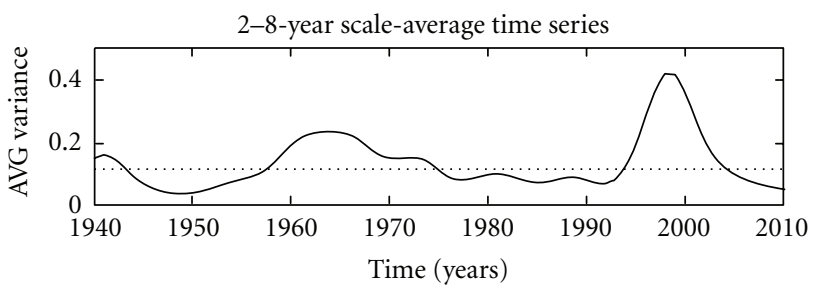

(d)

Figure 7: Freshwater discharge and water level in Ipanema (a), cross-wavelet between freshwater and water level in Ipanema (b), global wavelet spectrum (c), and average variance between 2 and 8 years $(d)$.

between the two variables can be observed clearly in years $1942,1966,1988$, and 2002.

The cross-wavelet analysis between the freshwater discharge and the SOI time series indicates the dominant length and period of the ENSO cycles that control the discharge (Figure 6(b)). It can be observed that between the years of 1950 and 1965 the dominant period was from 4 to 6 years, while from 1970 and 2000 the dominant period was lower than 4 years, indicating a change on the ENSO influence pattern on the region. The global wavelet spectrum (Figure 6(c)) showed the existence of well-defined cycles on interannual scales of approximately 3.8 and 6 years.

The average variance between 2 and 8 years is showed in Figure 6(d), where the periods that fit the 2 to 8 years cycle criteria are located above the dotted line (approximately 0.1 ). There are two peaks that can be highlighted on Figure $6(d)$ : between 1970 and 1975, a peak with an average variance of 0.2 , and between 1993 and 2001, a peak that reached an average variance of 0.4 , being the decade with the highest occurrence of ENSO events with a period of 2 to 8 years.

The direct relationship between freshwater discharge and water levels is presented on Ipanema (Figure 7(a)), São Lourenço (Figure 8(a)), and Rio Grande (Figure 9(a)). The variation pattern is very similar in all stations; the only difference presented is the lower amplitude of the water level on Rio Grande station. Peaks of freshwater discharge and water levels can be observed in 1965, 1983, 1998, and 2002.

The cross-wavelet analysis between the freshwater discharge and water level time series on Ipanema (Figure 7(b)), São Lourenço (Figure 8(b)), and Rio Grande (Figure 9(b)) stations indicates the length and period of the freshwater discharge cycles controlling the water level variability along 


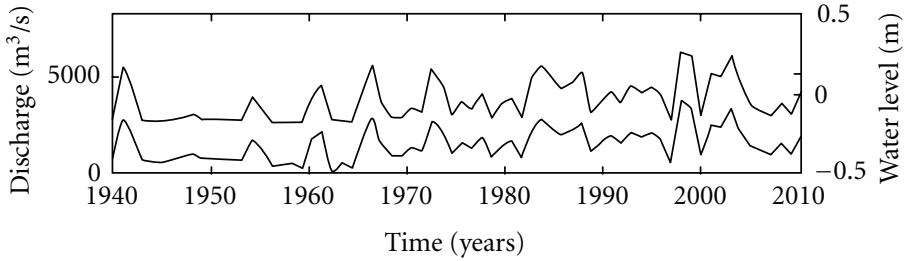

(a)

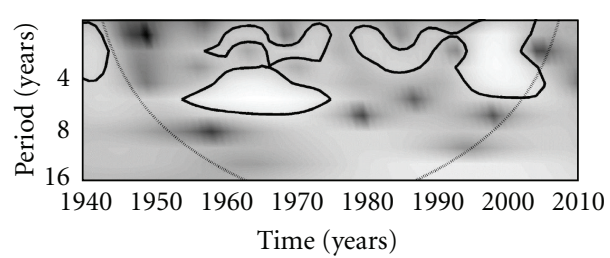

(b)

Global wavelet spectrum

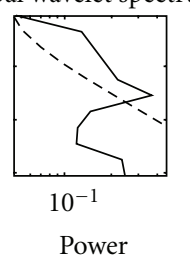

(c)

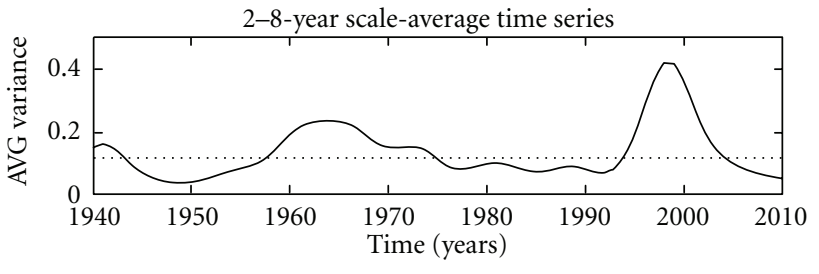

(d)

FiguRe 8: Freshwater discharge and water level in São Lourenço (a), cross-wavelet between freshwater and water level in São Lourenço (b), global wavelet spectrum (c), and average variance between 2 and 8 years (d).

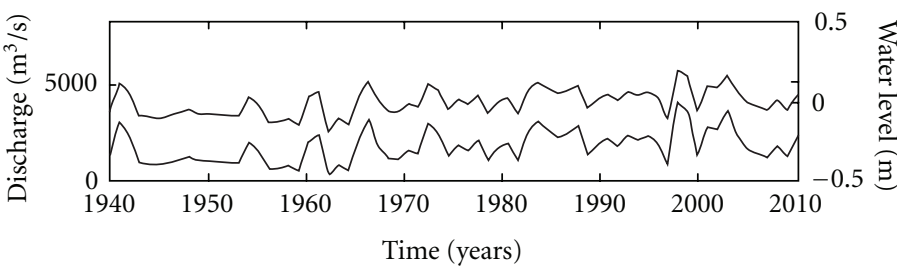

(a)

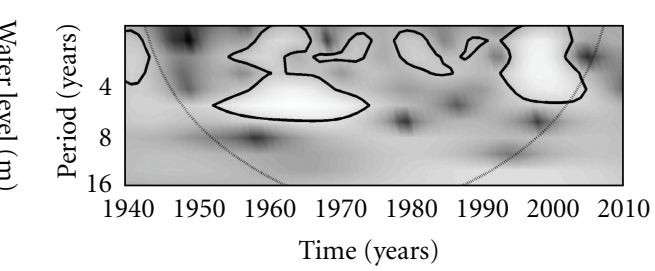

(b)

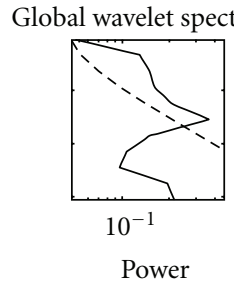

(c)

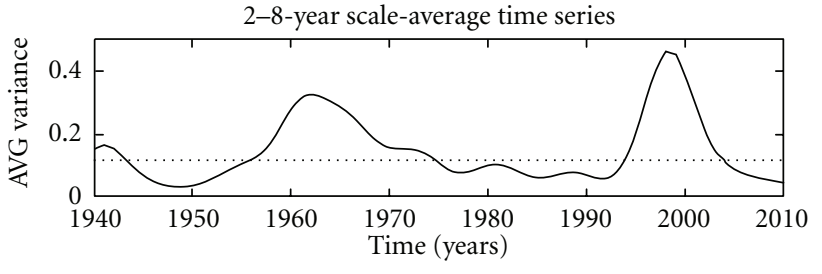

(d)

Figure 9: Freshwater discharge and water level in Rio Grande (a), cross-wavelet between freshwater and water level in Rio Grande (b), global wavelet spectrum (c), and average variance between 2 and 8 years $(\mathrm{d})$.

the Patos Lagoon. The cone of influence (dotted line) can be observed on the cross-wavelet spectrum figures; everything that is below it is considered as an error, as they are located on the edges of the image.

On Ipanema and São Lourenço, between 1956 and 1970 two cycles can be observed, one with a period lower than 4 years and another, more intense, with a period from 4 to 6 years. Another cycle is also seen from 1995 and 2002, with a period of 1 to 5 years approximately. On Rio Grande the pattern of the cycles observed is different from the other two stations. The cycle between 1956 and 1970 is similar to the other stations, but around 1960 the two cycles become one, increasing the intensity and range of period at this point, demonstrating that around 1960 the cycle had a period of 1 to 6 years. The other cycle (1995 to 2002) is also observed, but in this case it presents a time of occurrence lower than the other stations.

The global wavelet spectrum also showed the existence of well-defined cycles with interannual scales of approximately 3.8 and 6 years along the three stations (Figures 7(c), 8(c), and $9(\mathrm{c}))$. The global wavelet spectrum between SOI and freshwater discharge (Figure 6(c)) also presented these cycles, indicating that the ENSO is definitely controlling the freshwater discharge and water levels at Patos Lagoon in cycles from 3.8 to 6 years.

The average variance indicates in which years the cycles with 2 to 8 years length occurred. The three stations (Figures $7(\mathrm{~d}), 8(\mathrm{~d})$, and 9(d)) present two peaks of occurrence of cycles with 2 to 8 years: from 1957 to 1970 and from 1994 to 2003. Between 1940 and 1956 no cycles with those 
characteristics were observed, as well as between the years of 1972 and 1992. That can be explained by the occurrence of ENSO events with low intensity, that were not strong enough to influence the water level fluctuation.

Rio Grande station presented a higher value for the average variance in the first cycle (between 1956 and 1970). This higher value is probably associated with the fact that around 1960 the two cycles observed (one with a period lower and other higher than 4 years) became one, increasing the average variance value, reaching almost 0.4. Between 1995 and 2003 all three stations presented a cycle with high intensity (around 0.4), this period being the one with the most occurrence of strong ENSO events that influenced the water levels in the region.

\section{Discussion}

Regression analysis method can be used to find relation between different types of parameters; in this study the water levels were estimated as a function of freshwater discharge. Based upon this approximation, we assume that the model can represent the deterministic part of the water levels that are influenced by the most important processes that occur in interannual and decadal scales. The proposed model provides satisfactory results for preterit water level time series; therefore it could be used as boundary condition for numerical models or to fill small gaps in other time series along the Patos Lagoon.

The application of these methods allowed us to see that on interannual timescales the freshwater discharge explains about $80 \%$ of the water level variability on the lagoonar region. Therefore, on timescales longer than a year, freshwater discharge can be considered the main force controlling the residual processes in this region. Our results indicate that Patos Lagoon follows a pattern similar to Atchafalaya Bay, USA, where Swenson and Sasser [28] verified that freshwater discharge explains approximately $86 \%$ of water level variability on interannual scales. This high correlation is expected because interannual data is being used, reducing the importance of other forcing (e.g., wind) and increasing the freshwater discharge dominance.

At the estuarine portion of Patos Lagoon, freshwater discharge explains more than $50 \%$ of the water level variability. The other $50 \%$ can be explained by the remote effects associated with the adjacent ocean circulation due to its proximity to the mouth. Möller et al. [14] and Fernandes et al. [17] verified that the estuarine region of Patos Lagoon, in synoptic timescales, has the circulation pattern dominated by the local and remote wind action, with this influence being intensified in periods with low and moderate discharges. Our results indicate a similar pattern for water levels control in timescales longer than a year, but the importance of the effects associated to the wind was not investigated.

The delay between ENSO occurrence and precipitation anomalies was not observed on the results, because interannual data was used and the delay is observed on scales lower than years. According to Grimm et al. [29], there are consistent anomalies in the autumn winter of the year following El Niño all over southern Brazil. In La Niña years southern Brazil shows a well-pronounced and consistent dry season from September to December, with a peak in November and a strong decrease of magnitude in December [29]. Studies about the characteristics of the catchment (area, length, topography, vegetation, etc.) would be very important to identify the delay between an ENSO event, the precipitation anomaly associated to it, and the consequent increase of freshwater discharge, producing valuable information that could help in proper coastal management and flood prediction.

The variability pattern of the freshwater discharge is responsible for the maintenance of this environment over long timescales. Previous studies have shown that coastal lagoons are dynamically dominated by wind forcing [30], especially when the main axis is oriented by the predominant wind direction [31]. According to Möller et al. [13], Möller et al. [14], Fernandes [15], and Fernandes et al. [16], the Patos Lagoon dynamics in synoptic timescales is controlled by the longitudinal component of the wind that blows parallel to the coastline. In some regions the dominance of wind and freshwater discharge is very distinct in different timescales [32]. This is the case of Patos Lagoon: it is dominated by the wind on synoptic timescales and by the freshwater discharge on interannual timescales.

Freshwater discharge peaks that are not related to any El Niño event (e.g., 1962 and 1984) are probably associated with the passage of front colds. Total mean annual precipitation (1200-1500 mm) may strongly vary from year to year and is mainly related to the path and frequency of cold front passages [33]. Mean monthly rainfall is highest during the winter and spring (June to October), but a second peak may occur in summer [34], when daily precipitation occasionally exceeds $100 \mathrm{~mm}$.

At longer timescales, South America is affected by ENSO's influence [29, 35-37]. The most significant ENSO events show a high temporal variability, which may occur in near biannual scales (18-35 months) or in lower frequencies (32-88 months) [38]. Zhang et al. [39] analyzed global fields of sea surface temperature and divided the ENSO occurrence in an interannual scale and a residual scale with interdecadal variability.

El Niño is the South Oscillation phase where the trade winds are weak, the pressure is low over the eastern Tropical Pacific and high on the west side. The south region of Brazil shows precipitation anomalies associated with the ENSO occurrence $[29,36,40]$. In El Niño years, spring tends to be wetter, and in La Niña years droughts anomalies occur [29, 40]. In this study, it was observed that the main tributaries of Patos Lagoon show an intensification (decrease) in the mean freshwater discharge associated with El Niño (La Niña) years, on interannual scales (with cycles between 3.3 and 5 years). These results are consistent with analysis related to the SOI and agree with previously results obtained by other authors in this region of South America. Robertson and Mechoso [41] verified that El Niño years intensify the discharge in the rivers Negro and Paraguay in interannual variability scales (cycles between 3.5 and 6 years). Krepper et al. [42] found that freshwater discharge peaks of Uruguai River are also being influenced by ENOS, with scales of 3.5 to 6 years. 
Previous studies also indicate that freshwater discharge intensity and water levels show a variability pattern on decadal scales. Robertson and Mechoso [41] verified a cycle of approximately 9 years that is responsible for variability in freshwater discharge series at Paraguai and Paraná rivers. Those authors associated high discharges with low surface temperature at the North Atlantic Ocean, noticing that this component is stronger during the austral summer.

Negative anomalies of surface temperature of the North Atlantic tropical ocean during the austral summer are associated with the intensification of northeast winds and the movement of the Intertropical Convernge Zone to the south on ENSO scales $[43,44]$. These anomalies are also associated with linear trends observed between 1951 and 1990 [45]. Nogués-Paegle and Mo [46] suggest a possible influence of the tropical North Atlantic in the south region of South America through the summer monsoon system, on a decadal cycle, and by the wind flow toward south associated with a low-level jet along the east of the Andes.

The results presented previously do not allow us to identify a climatological event with a decadal cycle that influences the freshwater discharge pattern in this region; however the existence of these cycles and this influence on the freshwater and water level variability pattern of the Patos Lagoon should be investigated in a future research.

\section{Conclusions}

Time series analysis suggests that in annual timescales the freshwater discharge explains about $50 \%$ of water level variability at the estuarine region and more than $80 \%$ of the variability at the lagoonar portion of the Patos Lagoon. This result indicates that, on these timescales, freshwater discharge is the main forcing on the lagoon region. For this reason, we can expect that the residual dynamic processes in this area will be substantially influenced by natural climatological events that control the freshwater discharge of the main contributing rivers in this region. On the other hand, the pattern control of the water levels at the estuarine region is more complex, being influenced by the freshwater discharge variability and possibly by the remote effects associated with oceanic circulation.

The freshwater discharge of the main tributaries and water levels in Patos Lagoon is influenced by ENSO on interannual scales (cycles between 3.8 and 6 years); for this reason, El Niño (La Niña) events are associated with high (low) mean values of freshwater discharge and water levels above (below) the mean.

Ipanema and São Lourenço presented two cycles between 1956 and 1970, one with a period lower than 4 years and another, more intense, with a period of 4 to 6 years. Another cycle is also seen from 1995 and 2002, with a period of 1 to 5 years approximately. On Rio Grande the pattern of the cycles observed is a bit different from the other two stations. The cycle between 1956 and 1970 is similar to the other stations but around 1960 the two cycles become one, increasing the intensity and range of period at this point, demonstrating that around 1960 the cycle had a period of 1 to 6 years. The other cycle (1995 to 2002) is also observed, but in this case it presents a time of occurrence lower than the other stations.

The three stations (Ipanema, São Lourenço, and Rio Grande) presented two peaks of occurrence of cycles with 2 to 8 years: from 1957 to 1970 and from 1994 to 2003. Between 1940 and 1956 no cycles with those characteristics were observed, as well as between the years of 1972 and 1992. That can be explained by the occurrence of ENSO events with low intensity that were not strong enough to influence the water levels fluctuation.

The delay observed between an ENSO event and precipitation and freshwater discharge anomaly is usually lower than a year, so it is not possible to observe it on interannual time series. Further studies about the characteristics of the catchment (area, length, topography, vegetation, etc.) would be very important to identify the delay between an ENSO event, the precipitation anomaly associated to it, and the consequent increase of freshwater discharge, producing valuable information that could help in proper coastal management and flood prediction.

\section{Acknowledgments}

The authors are grateful to the Fundação de Amparo à Pesquisa do Estado do Rio Grande do Sul (FAPERGS) for sponsoring this research under contract 1018144. Further acknowledgments go to Brazilian National Water Agency (ANA) for supplying the fluvial discharge and for the Australian Bureau of Meteorology for supplying the SOI data set to accomplish this work.

\section{References}

[1] J. R. Schubel and D. W. Pritchard, "Responses of upper Chesapeake Bay to variations in discharge of the Susquehanna River," Estuaries, vol. 9, no. 4, pp. 236-249, 1986.

[2] T. A. Denes and J. M. Caffrey, "Changes in seasonal water transport in a Louisiana estuary, Fourleague Bay, Louisiana," Estuaries, vol. 11, no. 3, pp. 184-191, 1988.

[3] T. Yanagy, "Currents and sediment transport in the Seto Inland Sea, Japan," in Residual Currents and Long-Term Transport, R. T. Cheng, Ed., vol. 38 of Coastal and Estuarine Studies, pp. 348355, Springer, New York, NY, USA, 1990.

[4] R. J. Uncles and J. A. Stephens, "Buoyancy phenomena in the Tweed estuary," in Buoyancy Effects on Coastal and Estuarine Dynamics, vol. 53 of Coastal and Estuarine Studies, pp. 175193, American Geophysical Union, 1996.

[5] J. Dronkers, "The influence of buoyancy on transverse circulation and on estuarine dynamics," in Buoyancy Effects on Coastal and Estuarine Dynamics, D. G. Aubrey and C. T. Friedrichs, Eds., vol. 53 of Coastal and Estuarine Studies, pp. 341-356, American Geophysical Union, 1996.

[6] L. A. Cifuentes, L. E. Schemel, and J. H. Sharp, "Qualitative and numerical analyses of the effects of river inflow variations on mixing diagrams in estuaries," Estuarine, Coastal and Shelf Science, vol. 30, no. 4, pp. 411-427, 1990.

[7] I. Grabemann, H. Kühle, B. Kunze, and A. Müller, "Studies on transport times and water quality in the Weser estuary (Germany)," in Mixing in Estuaries and Coastal Seas, vol. 50 of Coastal and Estuarine Studies, pp. 291-302, American Geophysical Union, Washington, DC, USA, 1996. 
[8] P. H. Doering and R. H. Chamberlain, "Water quality and source of freshwater discharge to the Caloosahatchee estuary, Florida," Journal of the American Water Resources Association, vol. 35, no. 4, pp. 793-806, 1999.

[9] D. A. Jay, "Residual circulation in shallow estuary: shear, stratification and transport processes," in Residual Currents and Long-Term Transport. Coastal and Estuarine Studies, R. T. Cheng, Ed., vol. 38, pp. 49-78, Springer, New York, NY, USA, 1990.

[10] A. Y. Kuo, J. M. Hamrick, and G. M. Sisson, "Persistence of residual currents in the James River estuary and its implication to mass transport," in Residual Currents and Long-Term Transport. Coastal and Estuarine Studies, R. T. Cheng, Ed., vol. 38, pp. 389-402, Springer, New York, NY, USA, 1990.

[11] A. M. Garcia, J. P. Vieira, and K. O. Winemiller, "Dynamics of the shallow-water fish assemblage of the Patos Lagoon estuary (Brazil) during cold and warm ENSO episodes," Journal of Fish Biology, vol. 59, no. 5, pp. 1218-1238, 2001.

[12] O. O. Möller, Hydrodinamique de La Lagune dos Patos, Mésures et Modelisation [DSc. thesis], Université Bordeaux I, Talence, France, 1996.

[13] O. O. Möller, J. A. Lorenzzentti, J. L. Stech, and M. M. Mata, "The Patos Lagoon summertime circulation and dynamics," Continental Shelf Research, vol. 16, no. 3, pp. 335-351, 1996.

[14] O. O. Möller, P. Castaing, J. C. Salomon, and P. Lazure, “The influence of local and non-local forcing effects on the subtidal circulation of Patos Lagoon," Estuaries, vol. 24, no. 2, pp. 297 $311,2001$.

[15] E. H. L. Fernandes, Modeling the hydrodynamics of the Patos Lagoon, Brazil [Ph.D. thesis], University of Plymouth, Plymouth, UK, 2001.

[16] E. H. L. Fernandes, K. R. Dyer, O. O. Möller, and L. F. H. Niencheski, "The Patos Lagoon hydrodynamics during an El Niño event (1998)," Continental Shelf Research, vol. 22, no. 1113, pp. 1699-1713, 2002.

[17] E. H. L. Fernandes, K. R. Dyer, and O. O. Möller, "Spatial gradients in the flow of Southern Patos Lagoon," Journal of Coastal Research, vol. 20, pp. 102-112, 2005.

[18] M. L. Asmus, "Coastal plain and Patos Lagoon," in Subtropical Convergence Environments - The Coast and Sea in the Southwestern Atlantic, U. Seeliger, C. Odebrecht, and J. P. Castello, Eds., pp. 9-12, Springer, 1997.

[19] W. C. Marques, I. O. Monteiro, E. H. Fernandes, and O. O. Möller, "Numerical modeling of the Patos Lagoon coastal plume, Brazil," Continental Shelf Research, vol. 29, no. 3, pp. 556-571, 2009.

[20] A. Timmermann, J. Oberhuber, A. Bacher, M. Esch, M. Latif, and E. Roeckner, "Increased El Nino frequency in a climate model forced by future greenhouse warming," Nature, vol. 398, no. 6729, pp. 694-697, 1999.

[21] C. Torrence and G. P. Compo, "A practical guide to wavelet analysis," Bulletin of the American Meteorological Society, vol. 79, no. 1, pp. 61-78, 1998.

[22] I. Daubechies, "The wavelet transform, time-frequency localization and signal analysis," IEEE Transactions on Information Theory, vol. 36, no. 5, pp. 961-1005, 1990.

[23] W. J. Emery and R. E. Thompson, Data Analysis Methods in Physical Oceanography, B. P. C. Wheatons, Exeter, UK, 1st edition, 1998.

[24] B. M. Kendall and J. O. Blanton, "Microwave radiometer measurement of tidally induced salinity changes off the Georgia Coast," Journal of Geophysical Research, vol. 86, no. 7, pp. 6435-6441, 1981.
[25] M. E. Q. Pilson, "On the residence time of water in Narragansett Bay," Estuaries, vol. 8, no. 1, pp. 2-14, 1985.

[26] J. H. Simpson, W. G. Bos, F. Schirmer et al., "Periodic stratification in the Rhine ROFI in the North Sea," Oceanologica Acta, vol. 16, no. 1, pp. 23-32, 1993.

[27] D. Bourgault and V. G. Koutitonsky, "Real-time monitoring of the freshwater discharge at the head of the St. Lawrence Estuary," Atmosphere-Ocean, vol. 37, no. 2, pp. 203-220, 1999.

[28] E. M. Swenson and C. E. Sasser, "Water level fluctuations in the Atchafalaya Delta Louisiana: tidal forcing x river forcing," in Coastal and Estuarine studies 40: Dynamics and Exchanges in Estuaries and Coastal Zone, D. Prandle, Ed., pp. 191-208, American Geophysical Research, Washington, DC, USA, 1990.

[29] A. M. Grimm, S. E. T. Ferraz, and G. Julio, "Precipitation anomalies in southern Brazil associated with El Nino and La Nina events," Journal of Climate, vol. 11, no. 11, pp. 28632880, 1998.

[30] B. Kjerfve, "Coastal lagoons," in Coastal Lagoon Processes, B. Kjerfve, Ed., vol. 60 of Elsevier Oceanographic Series, pp. 1-8, Elsevier Science, Amsterdam, The Netherlands, 1994.

[31] N. P. Smith, "Water, salt and heat balance of coastal lagoons," in Coastal Lagoon Processes. Elsevier Oceanography Studies, B. Kjerfve, Ed., vol. 60, pp. 69-101, 1994.

[32] W. W. Schroeder, S. P. Dinnel, and W. J. Wiseman Jr., "Salinity stratification in a river-dominated estuary," Estuaries, vol. 13, no. 2, pp. 145-154, 1990.

[33] M. A. Gan and V. B. Rao, "Surface cyclogenesis over South America," Monthly Weather Review, vol. 119, no. 5, pp. 12931302, 1991.

[34] J. P. Castello and O. O. Möller, "On the relationship between rainfall amd shrimp production in the estuary of Patos Lagoon (RS,Brazil)," Atlântica, vol. 3, pp. 67-74, 1978.

[35] R. Allan, J. Lindesay, and D. Parker, El Niño Southern Oscillation and Climate Variability, National Library of Australia Cataloguing-in-Publication enty, Canberra, Australia, 1996.

[36] A. M. Grimm, V. R. Barros, and M. E. Doyle, "Climate variability in southern South America associated with El Niño and La Niña events," Journal of Climate, vol. 13, no. 1, pp. 35-58, 2000.

[37] M. D. Dettinger, D. S. Battisti, G. J. Mccabe, C. M. Bitz, and R. D. Gerreaud, "Interhemispheric effects of inter-annual and decadal ENSO-like climate variations on the Americas," in Interhemispheric Linkages, V. Markgref, Ed., pp. 1-16, Academic Press, 2001.

[38] E. M. Rasmusson, X. Wang, and C. F. Ropelewski, "The biennial component of ENSO variability," Journal of Marine Systems, vol. 1, no. 1-2, pp. 71-96, 1990.

[39] Y. Zhang, J. M. Wallace, and D. S. Battisti, "ENSO-like interdecadal variability: 1900-93," Journal of Climate, vol. 10, no. 5, pp. 1004-1020, 1997.

[40] A. Montecinos, A. Diaz, and P. Aceituno, "Seasonal diagnostic and predictability of rainfall in subtropical South America based on tropical Pacific SST," Journal of Climate, vol. 13, no. 4, pp. 746-758, 2000.

[41] A. W. Robertson and C. R. Mechoso, "Interannual and decadal cycles in river flows of southeastern South America," Journal of Climate, vol. 11, no. 10, pp. 2570-2581, 1998.

[42] C. M. Krepper, N. O. García, and P. D. Jones, "Interannual variability in the Uruguay river basin," International Journal of Climatology, vol. 23, no. 1, pp. 103-115, 2003.

[43] S. Hastenrath, L. C. De Castro, and P. Aceituno, "The Southern Oscillation in the tropical Atlantic sector," Contributions to Atmospheric Physics, vol. 60, pp. 447-463, 1987. 
[44] P. Aceituno, "On the functioning of the Southern Oscillation in the South American sector. Part I: surface climate," Monthly Weather Review, vol. 116, no. 3, pp. 505-524, 1988.

[45] R. G. Wagner, "Decadal-scale trends in mechanisms controlling meridional sea surface temperature gradients in the tropical Atlantic," Journal of Geophysical Research C, vol. 101, no. 7, pp. 16683-16694, 1996.

[46] J. Nogués-Paegle and K. C. Mo, "Alternating wet and dry conditions over South America during summer," Monthly Weather Review, vol. 125, no. 2, pp. 279-291, 1997. 

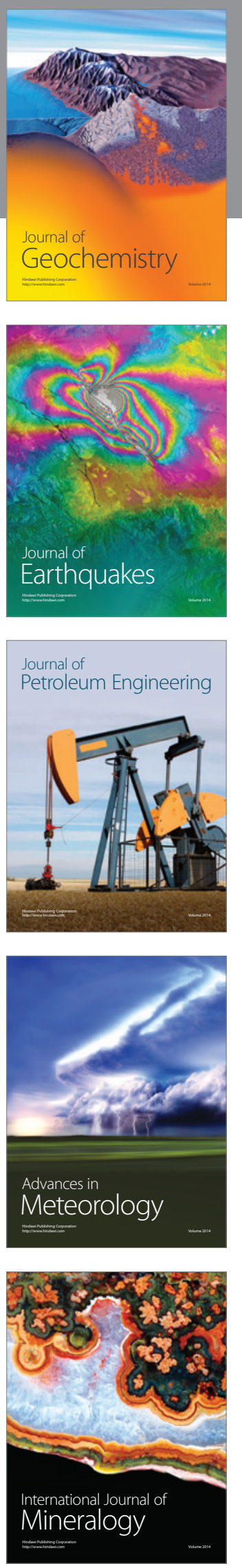
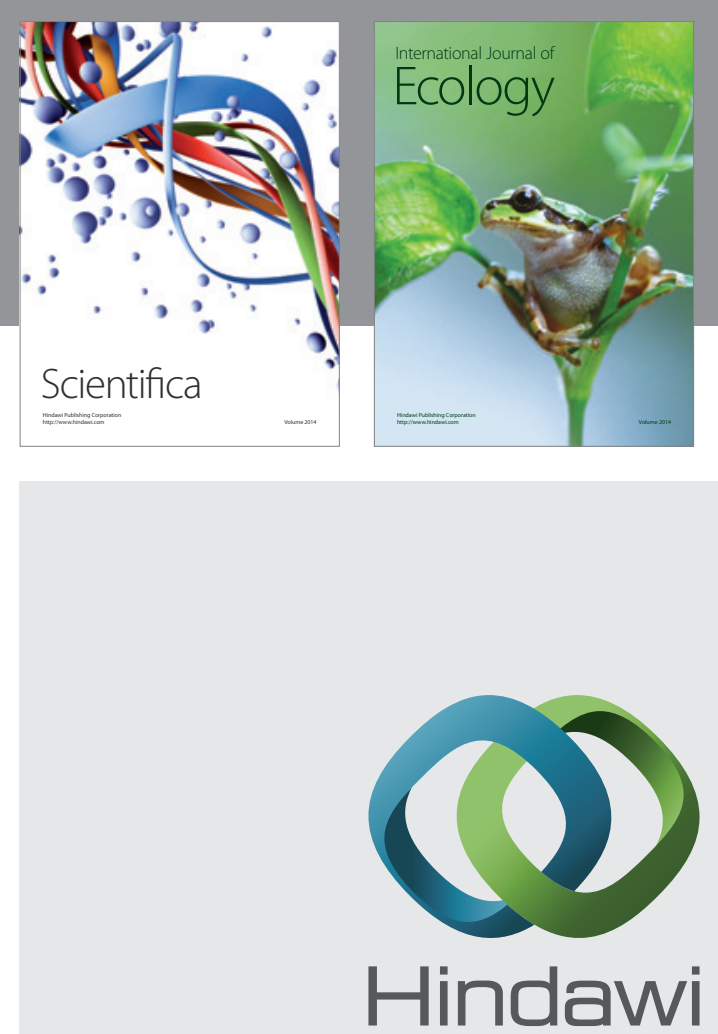

Submit your manuscripts at http://www.hindawi.com
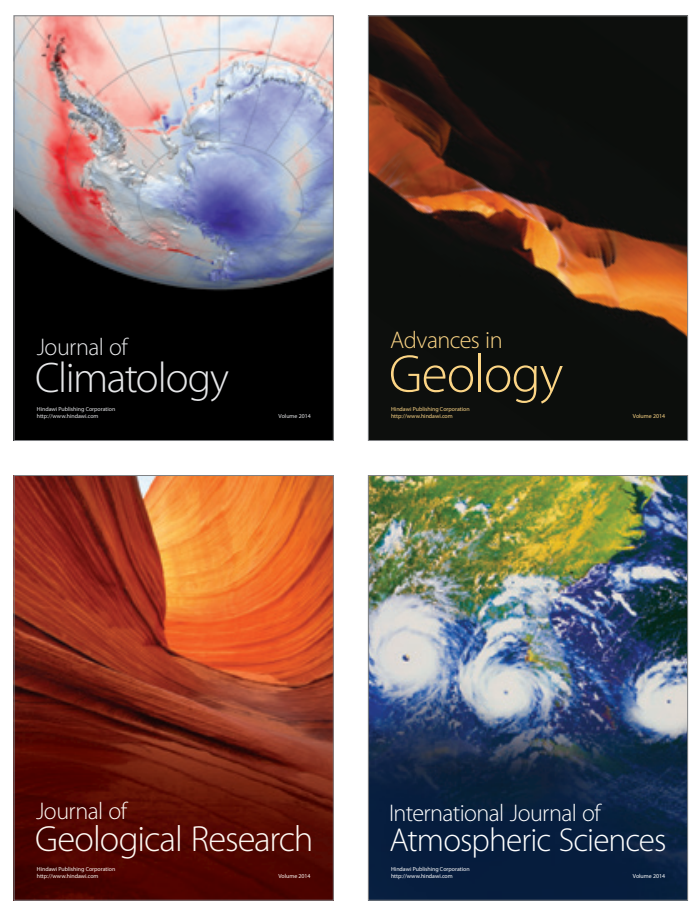
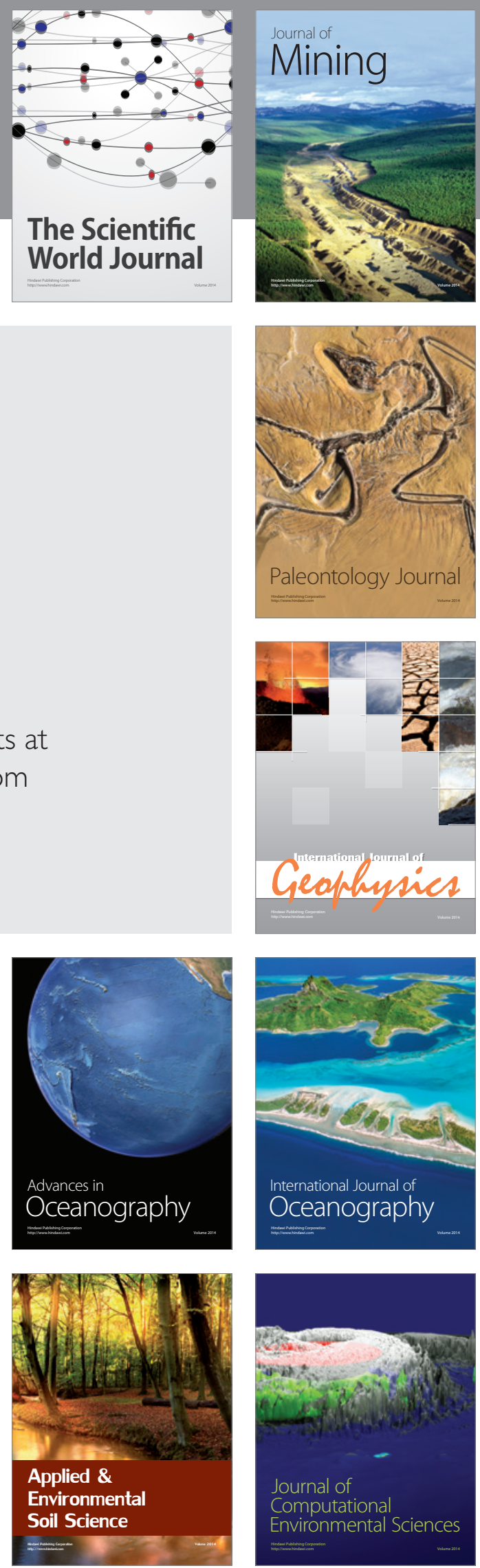